\title{
Fregean One-To-one Correspondence ANd Numbers as ObJect Properties
}

\author{
BORIS GROZDANOFF \\ University of Oxford
}

\begin{abstract}
The paper critically examines an unpopular line of Frege's view on numbers in the Foundations of Arithmetic. According to this view, which analyzes numbers in terms of properties and not in terms of extensions, numbers are properties of concepts vs. properties of objects. The latter view is held by Mill and is famously criticized in the Foundations. I argue that on the property account numbers cannot only be properties of concepts but they also have to be properties of objects. My main argument rests on purely metaphysical grounds. It stems from the motivation that were numbers only properties of concepts we would not have been able to explain mathematical truths about the physical world or those truths would have been miraculous. On pains that we do have mathematical truths about the physical world that are not miraculous we cannot agree with Frege's property line about the metaphysical nature of numbers.
\end{abstract}

Keywords: Numbers, properties, one-to-one correspondence, Frege.

Frege's view of the nature of numbers is perhaps the most influential one in $20^{\text {th }}$ century philosophy of mathematics, both in its richness and in the difficulties it raises (Frege 1884). In metaphysics it is widely accepted that Frege has refuted Mill's view on numbers as properties of objects as an untenable one (cf. Mill 1874). Attempts to defend reformulated versions of Mill's view are extremely rare: Philip Kitcher's recent one is perhaps the most notable (Kitcher 1998). And yet even Kitcher concentrates exclusively on the epistemic side of Mill's view. This side is all too often taken together with, and throws shadow over, Mill's metaphysical claim about the numbers as properties. Among the metaphysical attempts is the Lambros' modest view that "there are no compelling reasons why number words cannot be thought of as predicates of objects" (Lambros 1976, 381). Lambros' arguments are logically interesting and I take them as appealing, but his main aim is to vindicate the predicative use of number words, and where he draws metaphysical conclusions (Lambros 1976, 3845) they stem from a prevailing logical motivation rather than from a metaphysical one per se. In this brief paper I will offer metaphysical reasons for accepting within the property line view of the nature of numbers that, Millean or not, a conception of numbers as properties of objects is not merely an acceptable but a necessary one.

Principia 13(3): 327-38 (2009).

Published by NEL — Epistemology and Logic Research Group, Federal University of Santa Catarina (UFSC), Brazil. 
This perhaps unexpected thesis is suggested as one that does not contradict but that actually complements the reading of Frege's view of numbers in The Foundations of Arithmetic, according to which numbers are not simply self-subsistent objects but also properties of concepts. The paper certainly does not attempt the difficult task of developing this account; rather, it shows metaphysical reasons why it needs to be developed.

Famously, Frege argued that (1) numbers are self-subsistent objects that fall as extensions under concepts about equinumerosity (in paragraphs such as \#57 and \#69-\#74 in the Foundations) but he also argued that (2) numbers are properties of concepts (in paragraphs such as \#46). It is more or less uncontroversial that the leading view is (1) and yet (2) is what mainly stays behind Frege's criticism of Mill (in paragraphs as \#8, \#21-\#25). Also, it is (2) which captures best our numericallypredicative intuition for expressions like "The apples in the basket are five" $(P)$. The fact that we could, following Frege, translate such expressions into identities like "The number of apples in the basket $=$ five" $\left(P_{i}\right)$ does not annihilate the previous fact that predicative expressions like $P$ are well-formed and more often used than their $P_{i}$-type translations as identities. Also, and most importantly for the purposes of science, it is $P$-type expressions, and not $P_{i}$-type expressions, that capture the core of the applied mathematical language. The claim in The Foundations that Frege would not give up is the ontological thesis (1) and it is controversial whether he actually held (2), which is maintained simultaneously in the book, after he came up with (1). ${ }^{1}$ What is also controversial is whether both claims could actually be maintained together. My purpose is not to discuss these controversies but to examine the property line of Frege's theses and especially in connection with applied mathematical expressions like the those in \#70.

Let us assume that Frege's reading that numbers are not properties of objects is correct and that, were they properties of anything at all, numbers would have been solely and only properties of concepts (as he is explicit in \#46). In accordance with the context principle the main function of concepts within propositions is to say something meaningful and to contribute to propositional truths. To take Frege's well known example, let us imagine that there are (only) 52 cards on the table, in their original unopened pack (let us denote this state of affairs "S"). We cannot just ask the question "How many? (Q)" for we lack the sortal concept that would determine the number of what we are inquiring about: it might be the number of packs, the number of cards, the number of spots on the table, the number of spades, the number of whatever. So let us supply a sortal concept, say "cards", and ask our question, which takes the form of "How many cards are there on the table?" Now the question is correctly formulated and points to a specific, sorted state of affairs. The main semantic use of this and all similar propositions is to reach for their truth or falsity, among other things and through their being meaningful in the 
first place. The answer, given the concrete state of affairs, is "There are 52 cards on the table" $(P)$. Is this a correct answer? It seems so. If we deny that $P$ is meaningful we would harm the conception of sortal concept as carriers of numbers as properties. If we deny that it is true we would again harm the same conception as semantically useless, which would contrast with the striking intuitiveness and precision of mathematical truths. It seems then that we are compelled to accept that $P$ is both meaningful and true. The problem, however, with this is that $P$ attests not merely a fact about the state of affairs $S$ but attests a numerical fact about $S$. That is, it says not simply that there are cards on the table but that there are fifty two cards on the table. Did something change in $S$ between the reformulation of $Q$ into $P$ ? It obviously did not. Were there 52 cards on the table before we have even bothered to ask the question? There certainly were. Are there 97 cards on the table given $S$ ? There certainly are not. If there were a $Q$ answer to the $Q$ question $S_{Q}$ would have stayed exactly the same as $S_{P}$, whatever the semantic value of the $Q$ answer. This and similar counterfactual differences in $S$ are sufficiently interesting in order to be accounted for semantically, and numerically capturing the difference seems to be the most suitable and the most exhaustive way. Thus, there seem to be "reasons" in $S$ that on the one hand contribute to the meaning of $P$ and on the other hand, that sufficiently strongly participate in the truth of $P$. We can distinguish between two different problems for Frege here:

1. The "no change" problem

2. The "participation" problem

The no change problem claims that whatever sortal question we formulate and ask $S$ remains the same on the set of all possible reading of $S$ and especially on a numerical reading, the one that seems to be telling something precisely true about $S$ after the sortal question is asked. We might well have chosen any of the other possible questions "How many decks are on the table?", "How many packs are there on the table?", "How many Spades are there on the table?" and for every single one of them the state of affairs $S$ that would participate in the delivery of the true answerproposition would remain physically unchanged. The answers would contain, of course, different unions of sortal concepts and numbers (one deck, one pack, thirteen Spades) but what is there on the table that makes those at least partially true does not change on any reasonable understanding of "change". Frege sees and in a convincing manner the numbers coming from our conceptually sorted expressions. And we certainly do need sortal concepts to identify what we are inquiring about. But this pertains more to our knowledge of what it is a number of than to the nature of a number of per se: the first one is a cognitive attitude and the second one is a metaphysical.

Principia 13(3): 327-38 (2009). 
To inquire about the very nature of numbers is not to inquire about our knowledge of this nature: it is rather to ask a metaphysical question. Therefore, what Frege manages to do in a most brilliant way is to give the epistemic-semantic side of the problem. Where he commits a categorical mistake is when he reformulates the epistemic part as a metaphysically exhaustive one. Even if it is true that numbers are properties of the sortal concepts that serve to identify them, from this it does not follow that numbers are the only properties of sortal concepts. This is highly non-trivial and is seen best in "applied cases", typical for natural sciences. This leads us to the second problem, the "participation problem".

Whatever numbers are, how could we possibly have numerically true propositions about, say, the physical world, without the physical world is being numerically responsible for these truths? If this were indeed the case (and it would have been completely arbitrary whether there are 52 cards on the table or not, one electron in the hydrogen atom or not) the very truth of the propositions would not have exceeded a value beyond an arbitrary one. There are at least two reasons that rationally stop us from accepting this. The first one is the mind-boggling strength of pure mathematical truths and the second one, which ties it with things like the external world, is what Wigner famously called "unreasonable effectiveness of (pure) mathematics in naturals science" (Wigner 1960: 222). In cases of sufficiently successful physical theories, like the Standard model of Quantum Mechanics and General Theory of Relativity, the mathematical success of those theories is difficult to even comprehend properly. The parallelism between the pure truths of mathematics and the applied truths of our best scientific theories could not simply be a result of an arbitrary choice of a particular set of special concepts. There must be something in what the applied mathematical theories are actually about in order for this parallelism to take place and not some other. And the most simple metaphysical answer seems to be that numbers are both properties of sortal concepts and things those concepts (within propositions) are about. On this scenario we both keep our numericallypredicative intuitions for typical applied mathematical expressions and have at our disposal an account on which the success of pure mathematics in natural sciences is not miraculous anymore and is reduced to spelling out the proper coordination between one and the same properties, being possessed by different metaphysical carriers.

For Frege it is not sufficient that numbers are properties of concepts. He needs to establish a relation between that concepts that would preserve their numerosity in a meaningful way and this relation should be logical too. His insight is the notion of equinumerosity. Its function is crucial: within a principle (Hume's Principle) it delivers nothing less than the identity of numbers:

For any concepts, $F$ and $G$, the number belonging to $F$ is identical to the

Principia 13(3): 327-38 (2009). 
number belonging to $G$ iff $F$ and $G$ are equinumerous. (\#63, Hume's Principle.)

Equinumerosity is defined through an appeal to the extensions of the concepts that bear numbers as properties: two concepts, $F$ and $G$ are equinumerous when there is a one-to-one correspondence between the objects that fall under $F$ and $G$. In \#70 Frege writes:

If a waiter wishes to be certain of laying as many knives on a table as plates, he has no need to count either of them; all he has to do is to lay immediately to the right of every plate a knife, taking care that every knife on the table lies immediately to the right of the plate. Plates and knives are thus correlated one to one by the very means used, viz. The identical spatial relationship.

If numbers are taken to be only properties of concepts, then the relation between them, equinumerosity, has to be a relation only between concepts too. Yet, obviously, numerical truths seem to hold not just between logical entities but for, following Frege, things concepts are about, and therefore Frege needs to go beyond mere conceptual equinumerosity. In fact, he goes in a way even further. Conceptual equinumerosity is arrived at through the very notion of conceptual extension. We are presented with the following metaphysical picture: numbers receive their identity if and only if the concepts that bear them (while nothing else but concepts is able to bear them) are equinumerous. The concepts are equinumerous if and only if there is a one-to-one correspondence between the objects which fall (as their extensions) under them. The one-to-one correspondence is available, in Frege's example with knives and plates, through a "one" to "one" "correlation" which, in this particular case, is made possible through a sort of "spatial relationship". Besides the notion of equality (of a numerical sort, nevertheless) the notion of being numerised is what is precious in the notion of equinumerosity. For in order to be capable to participate in a relation of equi-numerosity the relata must be able to be of such a kind that something in them metaphysically allows an equality with respect to numerosity to be evaluated in the first place. For it is equality with respect to numerosity that delivers the crucial phenomenon of equinumerosity. The metaphysical sequence, which Frege depicts, must therefore demonstrate how the very notion of numerosity, the one which is at the heart of equality within the central notion of equi-numerosity, emerges in the first place. A critical inquiry must then investigate the metaphysical transfer from the source of the notion, whatever this turns out to be, to the notion of equinumerosity.

The first transfer is the transition from the notion of one-to-one correspondence to that of equinumerosity. This is more or less unproblematic: being one is the same as being of the number one and thus as being of a certain number (in this 
case one). The notion of numerosity is clearly preserved so the numerical transition faces no problem. In the above metaphysical setting, however, it is not at all obvious why numerosity should not be comprehended and rationally approached in terms of properties. For it is clear that it is not an object that is allegedly being carried from the source of whatever stays behind the notion of numerosity as it participates in Frege's central notion of equinumerosity. A property would do the job much more naturally. The numerosity meant here is certainly not merely a linguistic one: it is not a rudimentary conceptual discharge following purely linguistic recognition of the concept of numerosity within the higher complex order concept of equinumerosity. The numerosity inquired about here is the one that makes possible the very metaphysical ability of being capable of being a one in the first place. For in only such a way an entity could be related to another entity, whatever their metaphysical status might be, within the one-to-one correspondence relation, the relation that delivers equinumerosity.

There is another level of transition too, however, which is of a different metaphysical order: in The Foundations equinumerosity is a relation between concepts, but the relation of one-to-one correspondence is between objects that fall under concepts. The metaphysical distinction between concepts and objects is stressed in a quite straightforward way: we are supposed to reach equinumerosity of concepts from the numerosity stance of objects. This metaphysical level of transition is not so clear as the purely numerical one. But as far as Frege is concerned, concepts being objects is not so problematic either. What is more interesting is the next step: the metaphysical level of numerosity that is prior to one-to-one correspondence. This level should be a numerical source level for one-to-one correspondence and thus would be of utmost metaphysical interest. In \#70 Frege is quite clear about this level: it is the level of the physical entities knives and plates and not merely the level of the concepts "knives" and "plates". For the waiter is not putting the concept "knife" spatially next to the concept "plate" following some sort of a "spatial relationship"; such relationship could not exist among concepts. The waiter has not to count real physical knives and plates and again not their concepts. Thus the entities that have to be in a one-to-one correspondence are from the level inhabited by the physical objects "knives" and "plates". The last sentence in the quotation from \#70 is that "Plates and knives are thus correlated one by one (my italics)". The metaphysical level is defined as clearly as it could be. It is plain that the things to be one-to-one corresponded are classical physical entities. ${ }^{2}$ Yet, the notion of numerosity exists quite alive here as well: the notion of "one" is a numerically full-blooded notion. And it is metaphysically crucial. For it delivers what is to be preserved through the transitions until it reaches equinumerosity: numerosity itself. Knives and plates are not just "spatially ordered" but they are also numerically individuated, that is, they are of some number and this number in every case of an individual entity as "knife"

Principia 13(3): 327-38 (2009). 
and "plate" is suspiciously difficult to distinguish from the natural number one. Only in virtue of this could a knife and a plate be one-to-one, that is, due to their being numerically individuated in the most primitive metaphysical way, numerically ordered with respect to each other in some sort of way. And the number one seems to stay in relation to the entities as a property of theirs in no lesser way as it stays as a property of a Fregean concept. No one-to-one correspondence is conceivable with no oneness being present. And spatial relationship, being a geometrical relationship, might deliver a numerical individuation, that is, it might individuate an entity in such a way that it becomes rationally approachable with respect to its metaphysical status as one entity. But it is only in virtue of the entity being one entity that it could participate in a one-to-one correspondence relation and not merely in virtue of its being 3 centimetres on the right of some other entity.

Thus, a notion of numerosity seems to be present in the bottom Fregean metaphysical level as well. And here the problem rises its ugly head, for this being the last metaphysical level in the story at hand, there is no other possible metaphysical source to take numerosity from. And if numerosity is present in all metaphysical levels this means that we simply track a property of the inhabitants of all those metaphysical levels, a property they all share as common. Yet, as it was stressed above, not all of those inhabitants are concepts. Knives and plates are physical entities and such entities are of metaphysically different category. This being the case, however, numbers could not be just properties of concepts for they appear to be as much properties of physical (as any other objects of course too: and primarily abstract objects) entities as properties of concepts. Freges's metaphysical theory about numbers is in this aspect incomplete and in its incompleteness it fails. In order for a one-to-one correspondence to be possible there have to be "ones" beforehand available. The "ones" do not somehow emerge in virtue of correspondence and so do not receive their numerical individuation by merely being put one-to-one. The "ones" make possible the one-to-one-correspondence in the first place. There does not seem to be a meaningful way of a talk about one-to-one correspondence unless the elements put in such a correspondence are independent of the relation of numerical individuation; the one that comes along with, perhaps, their standard property individuation. Therefore, conceptual one-to-one correspondence could not serve as a way to define numerosity, the heavy burden Frege puts on it in the Foundations of Arithmetic. Because numerosity is already at hand, the conceptual one-to-one correspondence simply inputs already numerically individuated metaphysical elements. The effect of this is far reaching - no definition of numerosity could succeed if based on the exposed as non-primitive notion of conceptual one-to-one correspondence.

Equinumerosity delivers no other kind of identity but the numerical identity of concepts: two concepts are equinumerous if and only if it is possible to coordinate the objects that "fall" under them in such a way so that they are related in the 
alleged "one-to-one correspondence". In \#70 Frege illustrates this coordination with the spatial example of knives and plates. In such physical cases it is clear that in order to have one-to-one coordination we need not merely a linguistic and logical distinction between a knife and a plate. For the waiter physically distinguishes one from the other by doing a sort of physical coordination: putting one next to the other. The fact that I can only approach the physical domain through concept does not annihilate its categorically distinct properties. Certainly, the waiter needs to have a rational grasp of the difference but without the physical counterpart of the rational difference between a knife and a plate he would have been unable to physically coordinate them next to each other. Yet, an objection might have it, we do not really need a physical coordination at all in order to have a one-to-one coordination. All we need is the rational one. Appealing as this is, this depends on the given situation. For some situations we really do not need it, and for some we do; for example, in situations when we do not have a rational grasp of what is to be coordinated with what we seem to be unable to pass without it.

To illustrate, imagine two baskets full with things that the coordinating agent is not aware of. And she is asked to put one entity from the basket A next to an entity from a basket $\mathrm{B}$ on a table but without looking into the baskets. If the entities have random sticky sides they will form a sort of aggregate, to use Mill's expression, but the agent would not be able to predict what aggregate would be formed. For the aggregation would be, besides the initial physical conditions in the basket, formed entirely due to her putting her hands in the basket and changing the geometrical configuration of the sticky sides while trying to "take a physical object". Now, in this and in similar cases, it is obvious that at the time of the coordination (let's furnish the example by her not seeing and not feeling the true configuration of the aggregate even during her taking it out of the basket and even when putting it on the table: we can conceive of suitable weight and swinging behaviour of the sticky entities, perhaps even electronically adjusted in real time, such that she would not know how many of them would form an aggregate; she would only learn the randomly occurred aggregation that would form an entity to be one-to-one coordinated when she looks at it on the table) the agent has a rational grasp neither of the conditions of the individuation of the objects nor of the exact aggregates to be coordinated with each other. In such an occasion we would have a physical coordination of oneto-one aggregates from basket A and basket B but we would not have the rational coordination. In the best scenario we would have some sort of a false perceptual feeling which even if leading to a rational belief (which is not necessary at all: the agent might be aware that what she feels is in most cases not the actual aggregate formed; or we could just leave her to think what she wants and in this case she would end up having a false rational coordination about the objects to be coordinated) that differs from the physical coordination on the table; the agent might think that there 
are two by two coordinated entities while there are actually not and there is just one A entity on the one side put in one-to-two correspondence with two B entities. This case might be reached for when an aggregate put on the table sticks to another already on the table and she is not aware of this: given that the most intuitive conditions of individuations of objects of coordination are not the sticky elements of the aggregates but the aggregates themselves (we could complicate the experiment even more by eliminating spatial individuation of separate elements at all by making them completely lose the element identity they have from the time in the basket but this does not seem necessary for the point).

An immediate objection might argue that the basket situation shows nothing above a merely epistemic problem and thus it is not a problem for metaphysics. Such objection, nevertheless, fails. For obviously there is an epistemic component in the thought experiment and at that one that does not look comfortable for Frege's a priori attitude. But the metaphysical point is the central one: how could the one-toone correspondence be numerically independent from the properties of the objects if it is a correct correspondence? How do we know that the concept "knife" and the concept "plate" are equinumerous in Frege's illustration from \#70 if there is one knife on the table and 5 plates? Obviously there is no one-to-one correspondence between the knives and the plates. But how do we know that? Besides the epistemic story, which in the case of properties of physical objects would be one or another version of the contemporary empiricism, such as the one recently being offered by Philip Kitcher and particularly for mathematical cases, there should be something in the domain of observation that allows for the correct participation of the objects in the rational one-to-one correspondence. And this is metaphysical enough.

Another objection might stem from the power of rationality. What if the basket case is not possible without concepts? What if the agent could not and actually does not coordinate the A aggregates and the B aggregates if she does not have the relevant concept tied in proper propositional relations? This objection does not manage to deliver the goods too. We can imagine an inanimate machine, not even a robot, which by random repetition performs the same coordination. It has neither concepts nor what we would call "rationality". We would have the same physical result. In this case the question about the relevance of the entity individuation of the randomly coordinated aggregates would matter, of course, not for the machine, which is not a rational agent, but for any rational agent, who is interested in the problem. Is the result of the machine coordination relevant for such cases? Well, when entertained by a rational agent who attempts to define a one-to-one correspondence between the As and Bs this is a most relevant result. And an agent who wishes to clarify the subject sufficiently well could not allow herself to ignore such cases. We should be philosophically interested about such cases as if they were attempted as one-to-one coordinated. Merely ignoring the case as irrelevant would not help much. 
Similar illustrations show that the physical portion of the coordination is not merely dispensable with but necessary for Frege's extension conception. For all scientific knowledge which deals with the physical world needs physical objects, the same ones which in virtue of being an extension of the concepts to be equinumerous, need to be equinumerous as well. And in failed coordinating cases like the above basket case, even if we form propositions about the coordination it would be a coordination that would not be true by not being isomorphic to the primitive structure of the natural numbers. For applied mathematical cases, the physical portion of the coordination, that is, to use Frege's wording, the physical portion of the one-toone correspondence, is a necessary part which is not linguistic. And for successful cases like the one of knives and plates, we obviously need something in the physical world that would allow us to get the rational coordination right too. This something has the heavy responsibility to deliver the physical conditions of the possibility to physically individuate an entity that could physically and rationally participate in a one-to-one correspondence. The best candidate for such "something" is most suitably captured in terms of the familiar numerical properties, not so different from the ones put forward by Mill in The System of Logic and criticized somewhat hasty by Frege in The Foundations.

The extension portion of Frege's famous view on the nature of numbers proved to be untenable in view of the Russell's paradox or, in the best possible scenario, proved to be in a need of heavy modifications in order to become vital. The property portion is a separate case. Thoughts in terms of properties are intimately connected with quantitative expressions and numerical ones in particular. On the suggested above account the property portion of Frege's view is accepted and complemented, unexpectedly, with a neo-Millean sort of view according to which numbers are also properties of objects, be they classical physical entities or more exotic objects like abstract ones. The truths of applied mathematics thus need not be miracles anymore. In truthful natural scientific cases we will have a successful match between a set of conceptual properties $S_{C}$ and a set of object properties $S_{O}$. The mapping is a task for the philosophy of science but by no means a miraculous one. History of Philosophy of Science shows that from Reichenbach's famous principles of coordination to Michael Friedman's contemporary account of constitutive a priori principles there are non-miraculous positions struggling to spell out the coordination. Together with prevailing naturalist doctrines like the neo-Millean one of Philip Kitcher of applied mathematical truths they shape a significantly rich body of philosophical choices, which could now be metaphysically shown to be internally coherent given the now common metaphysical account of mathematical properties as belonging both to the abstract and the physical domains. ${ }^{3}$

Principia 13(3): 327-38 (2009). 


\section{References}

Frege, G. 1884. Die Grundlagen der Arithmetik. (References to the paragraphs of this work are to the English translation, The Foundations of Arithmetic, translated by J. L. Austin, $2^{\text {nd }}$ rev. edition, Illinois: Northwestern University Press, 1980.)

Kitcher, P. 1998. Mathematics and the Naturalist Tradition. In J. Skorupski (ed.) The Cambridge Companion to Mill. New York: Cambrigde University Press.

Lambros, C. 1976. Are Numbers Properties of Objects. Philosophical Studies 29(6): 381-9.

Mendelsohn, R. 1989. On an Alleged problem for Frege's account of number. Philosophical Studies 56: 193-7.

Mill, J. S. 1874. A System of Logic. New York: Harper \& Brothers.

Minogue, B. 1977. Numbers, Properties, and Frege. Philosophical Studies 31: 423-7.

Wigner, E. 1967. The unreasonable effectiveness of mathematics in the natural sciences. In his Symmetries and Reflections. Bloomington: Indiana University Press, p. 222-37.

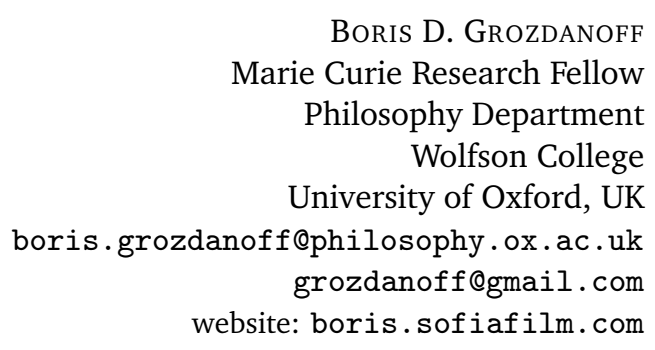

Resumo. Este artigo examina criticamente uma linha impopular da concepção fregeana de número nos Fundamentos da aritmética. Segundo essa concepção, que analisa números em termos de propriedades e não em termos de extensões, números são propriedades de conceitos vs. propriedades de objetos. Essa última concepção é sustentada por Mill e celebremente criticada nos Fundamentos. Sustento que na explicação de propriedade os números não podem somente ser propriedades de conceitos mas também têm que ser propriedades de objetos. Meu argumento principal baseia-se em razões puramente metafísicas. Origina-se da motivação de que, se números fossem somente propriedades de conceitos, ou não seríamos capazes de explicar verdades matemáticas sobre o mundo físico ou essas verdades seriam milagrosas. Considerando que de fato temos verdades matemáticas sobre o mundo físico que não são milagrosas, não podemos concordar com a concepção de propriedade de Frege acerca da natureza metafísica dos números.

Palavras-chave: Números, propriedades, correspondência biunívoca, Frege.

\section{Notes}

${ }^{1}$ For a discussion on the controversy see Minogue 1977, 423-7 and Mendelsohn 1989, 1937.

Principia 13(3): 327-38 (2009). 
${ }^{2}$ A knife is metaphysically possible only as one knife. The very term "knife", when it refers to the real physical object "knife", is meaningful only if it denotes something numerically individuated. An entity comes with its numerical individuation.

${ }^{3}$ This paper has been written while I was a Marie Curie IEF Fellow at the University of Oxford and all the help of the EC is gratefully acknowledged.

Principia 13(3): 327-38 (2009). 